\title{
Guiding Commitments and Criminal Liability for Attempts
}

\author{
R A Duff
}

Gideon Yaffe's Attempts is a remarkable book: ${ }^{1}$ remarkable in its philosophical sophistication and ingenuity, remarkable in the imaginative and original solutions it offers to a range of issues in the criminal law of attempts that have puzzled generations of lawyers and philosophers. Many who have grappled with these issues share Jerome Hall's eloquent view that

[w] hoever has speculated on criminal attempt will agree that the problem is as fascinating as it is intricate. At every least step it intrigues and cajoles; like la belle dame sans merci, when solution seems just within reach, it eludes the zealous pursuer, leaving him to despair ever of enjoying the sweet fruit of discovery. (Hall 1940: 789)

Readers of Yaffe's book will also find it 'as fascinating as it is intricate'; they will be intrigued and cajoled - and at least sometimes they will enjoy 'the sweet fruit of discovery', as they come to see how work in the philosophy of action can illuminate problems in criminal law. As is often the way with occasions of this kind, my paper will focus not on the aspects of the book, or on the arguments and theses, that seem to me to be successful, but on one significant respect in which I think it fails to achieve what Yaffe aims to achieve - to ground a normatively plausible criminal law of attempts in a rigorous philosophical analysis of what it is to try to act. However, I would not want my comments to appear grudging or nitpicking (although some nits will be picked, this will be in the service of larger aims): the book substantially deepens our understanding of the law of criminal attempts, and should radically change (for the better) the terms of future debates.

Central to Yaffe's overall argument is what he calls the 'Guiding Commitment View' (which will hereafter be labelled $G C V$ ) of what it is to try or attempt to act. Its canonical formulation is:

The Guiding Commitment View: D attempts $\mathrm{C}$ if and only if $\forall \mathrm{Ei}$, the following criteria are met:

Commitment Criterion: ((Ei is included in X) OR (If D's intention plays its proper causal role, then Ei)), \&

Guidance Criterion: D is guided by his commitment to $\mathrm{Ei}$ (p. 73)

In the context of criminal attempts, $\mathrm{C}$ is a crime; E1, E2 ...En are the elements of the crime as it is defined by the law; $\mathrm{X}$ is the content of D's intention. To put it very roughly indeed, D commits a criminal attempt, on this view, if and only if he is practically guided by his commitment to each of the elements of the offence in question.

In what follows, I will raise a number of questions about the adequacy of $G C V$ : not primarily about its adequacy as an account of attempting or trying (though some questions will bear on that issue), but rather about its adequacy as the core of an account of how we should formulate and understand a law of criminal attempts. In section 1, I will argue that it is too broad as an account of what it is to try to act, and that although Yaffe offers an interesting argument that it would not generate too expansive an account of what it is to be guilty of a criminal attempt, it still generates an implausibly expansive account of what it is to commit an attempt. In section 2, I will argue that, on the other hand, Yaffe does not do enough to justify a law of criminal attempts rather than

Yaffe 2010; future bare page references in the text of this paper will be to this book. 
a much more expansive general law of inchoate or non-completed crimes that includes reckless actions which do not in fact cause the harm that they risk causing: if the arguments in these two sections are right, Yaffe's account is thus both too broad and too narrow. Finally, in section 3, I will argue that Yaffe's efforts to show how $G C V$ can help us deal with some vexed issues about the circumstantial aspects of a criminal attempt also fail: 'commitment' cannot do as much work as he needs it to do.

\section{Attempts and Preparations}

$\mathrm{D}$ decides to rob a shop, but realises that he is not as physically fit as he once was. So he decides that, in order (and only in order) to get himself fit enough for the robbery, he will start eating a newly advertised cereal for breakfast every day, believing (since he is a sucker for the kinds of advertisement that boast the health-giving properties of miracle foods) that within a week he will be fit enough to overcome any resistance by the shopkeeper. ${ }^{2}$ He needs to go out to buy supplies of the cereal, and so takes his shoes from the wardrobe to put them on; were it not for the need to go out to buy the cereal, he would not put his shoes on. Here then are actions that D undertakes - taking his shoes from the wardrobe, putting them on, going to the supermarket, buying cereal, eating it for breakfast - as means to his intended robbery of the shop. There are of course plenty of ways in which, even if D successfully undertakes these actions, the robbery might not take place; indeed, he might not even get as far as going into the shop to rob it. His enterprise might be interrupted by human or natural forces: he is arrested and locked up (for another crime); he is struck down by illness. He might change his mind, thanks to a moral awakening, or because he is offered a new and more attractive way of making money. And so on. At the time when he takes his shoes from the wardrobe, however (indeed at the time when he tries to open the jammed door of the wardrobe to get his shoes), it seems that on Yaffe's account he is already trying to rob the store. For his intention to rob the store includes, we can suppose, every element of the crime of robbery, so that he satisfies the Commitment Criterion; and he is guided by that commitment, in that he acts as he does because he has that intention. More precisely, it seems that he satisfies the Completion Counterfactual by which Yaffe specifies the content of the Guidance Criterion (pp. 90-98): for, taking $t_{1}$ as the time at which he tries to open the wardrobe, and $t_{2}$ as the time when, according to his plan, the robbery will take place, it seems to be true that

If (1) from $t_{1}$ to $t_{2} D$ has the ability and the opportunity to [rob the store] and does not fall

prey to 'execution failure', and (2) D does not (at least until after $\mathrm{t}_{2}$ ) change his mind, then

D would [rob the store] (p. 94). ${ }^{3}$

It is also true at $t_{1}$ that $\mathrm{D}$ intends to rob the store, and tries to open the wardrobe and believes that opening the wardrobe is a means to robbing the store and tries to open it for that reason; so if we can also suppose that $\mathrm{D}$ is rational (and we have no reason not to suppose this, even if he is a bit

2 This example builds on one of Yaffe's examples: see p. 281, on 'mere preparation'.

3 Might Yaffe say that in this case D is motivated to [open the wardrobe] because he intends to [rob the store]. But he is not, when he is [opening the wardrobe] trying to rob the store', because 'what motivates his [opening the wardrobe] is not the intention to [rob the store], but, instead, the intention to [open the wardrobe], an intention that he formed as a result of the fact that he intends to [rob the store]' (p. 93)? But Yaffe allows that someone like D could be 'acting on the intention to reach the end', which is all that I need here. 
gullible when it comes to advertisements for miracle foods), then Yaffe holds that 'at $t_{1} D$ tries to perform all the acts that are necessary means to' robbing the store (p. 230).

It might seem to follow from this that Yaffe would hold D to be guilty of attempted robbery as soon as he tries to open the wardrobe door (if not sooner): for although that is not the 'last act' required for the robbery (indeed it is close to the first act), it 'is performed as a means to' robbing the store, and D is (so far as we know) 'both practically competent and rational' (p. 272). ${ }^{4}$ But he does not in fact think that the law of attempts should be so formulated and applied that the court would be entitled to convict D of attempted robbery. Even if it is in fact true, as my story has it, that what motivates D to try to open the wardrobe door is his intention to rob the store, to which he sees this action as a means,

we can think of many other intentions that would motivate that behaviour, so, even if we have no reason to think that $\mathrm{D}$ has any of those other intentions, we still lack sufficient evidence from which to infer that he performs the relevant act as a means to completing the robbery (pp. 281-2).

This brings us to two further important features of Yaffe's account. The first is the distinction he draws between commission and guilt, ${ }^{5}$ given which it might be true that $\mathrm{D}$ committed a crime, or attempted to commit a crime (according to the criteria specified in $G C V$ ), but not true that a court would be entitled to convict him - to hold (or to make?) him guilty of that crime or that attempt. The second is his argument (chs. 8, 10) that the act requirement in attempts must be understood in evidential terms: the law requires 'action in furtherance of' the criminal intention because such action provides 'indispensable evidence of trying, and there are good reasons not to punish even the deserving in the absence of adequate evidence (p. 255). Thus what gets $\mathrm{D}$, the intending store robber, off the hook as far as the criminal law is concerned is not the fact that he is not trying to rob the store-for we have seen that he is, on Yaffe's account, trying to rob it; nor is it just that the prosecutor might in fact find it hard to adduce sufficient evidence in court that D's attempted wardrobe opening was part of an attempt to rob, i.e. was undertaken as a means to robbing, the store: if I understand Yaffe right, if the only conduct that the prosecution can establish is of this kind, the act requirement is not satisfied. We might not then be able to say even that D commits a criminal attempt at robbery, if the law of attempts is so formulated that D's wardrobe opening is to be classed as 'mere preparation' rather than as attempt; but I think we (or rather Yaffe) must say that D commits an attempt at robbery as soon as he tries to open the wardrobe door, and is as culpably deserving at least of censure as is someone who completes the robbery, even if for good reason the law should not hold him guilty of a criminal attempt. ${ }^{6}$

4 This is part (covering acts that are not last acts) of Yaffe's first specification of the act element of an attempt.

5 The distinction is first explained at p. 110, in the context of noting that commission is not necessary for guilt: an accomplice can be guilty, i.e. properly convicted, of a crime that he did not commit.

6 The claim that he is as deserving of censure, i.e. that he deserves as much censure, as one who completes the robbery depends on Yaffe's arguments in ch. 12 that one who completes an attempt is as deserving of censure as he would have been if his attempt succeeded, and that we have no good reason to punish incomplete attempts any less severely than we would punish them were they completed. I cannot discuss those arguments here, but note that the second depends on what seems to me the dubious claim that one who completes an attempt and one whose attempt is interrupted before completion have '[i]n one very important respect ... done precisely the same thing: they have both tried to commit the crime' (p. 326): that fits with the claim that 'D tries to perform all the acts that are necessary means to' robbing the store (p. 230), but I will argue that we should reject it. 
These results seem implausible, both in relation to what we should count, independently of the criminal law, as attempting or trying, and in relation to the criminal law.

If someone asks me what D is doing, as he struggles with the wardrobe door, and I reply ' $\mathrm{He}$ is trying to rob a store', my interlocutor will be puzzled: how is opening a wardrobe door a way of robbing a store (unless the door is actually the door to a well disguised store). If I explain that $\mathrm{D}$ is trying to open the wardrobe to get his shoes to go to the supermarket to buy the cereal that will build his strength to enable him to rob the store successfully, my interlocutor will now know what $\mathrm{D}$ is about, but will surely still be entitled to accuse me of offering an initial reply that was not merely under-informative, but false: $\mathrm{D}$ is not yet trying to rob the store. He has certainly got beyond mere contemplation, beyond intention-formation, beyond even planning (at least initial planning), and is beginning to put his plans into effect; he is committed to the robbery, and his actions are guided by that commitment; he also intends at $\mathrm{t}_{1}$ (the time when he tries to open the wardrobe) 'to perform all the acts that are necessary means to' robbing the store (p. 230): but it seems wrong to say that he is already trying to rob the store, or indeed trying to perform all the other acts that he takes to be necessary means to that end; he is at the stage of preparation, not of attempt. That is, of course, assertion rather than argument, and is not an assertion that I could back up by the provision of a revised version of $G C V$ which would enable us to draw a sharp distinction between (mere) preparation and attempt-nor indeed do I believe that any such sharp distinction can be drawn. But if I am right both that on Yaffe's view D is trying to rob the store, and that in our ordinary extra-legal discourse it would be false to say that $\mathrm{D}$ is trying to rob the store, then it follows that $G C V$ is inadequate, or at least incomplete, as an account of attempting or trying. ${ }^{7}$ It is, I think, plausible to say that D attempts $\mathrm{C}$ only if both Commitment and Guidance criteria are met; but not that $\mathrm{D}$ attempts $\mathrm{C}$ just so long as both criteria are met.

Not only does it seem false to say that $\mathrm{D}$ is attempting to rob the store as he tries to open the wardrobe door; it seems wrong to say that he is as deserving of the kind of censure that a criminal conviction and punishment serve to convey as he would have been had he completed or come much closer to completing an attempt to rob the store-that what should save him from criminal guilt is the lack of appropriate evidence that he was trying to rob it. He is of course censurable for forming the intention to rob the store and making plans to commit the robbery; indeed, although we cannot talk straightforwardly of his 'conduct', we can say that his practical deliberation is 'a product of a faulty mode of recognition or response to reasons for action' ( $\mathrm{p}$. 38). If he is already firmly committed to the robbery, if it is true that he would carry it through unless something prevented him (suppose he is a person whose intention formation and planning are always serious, and who sticks to his plans), we could also say that he already displays a serious defect of character. But, first, he does not seem to become significantly or categorically more deserving of censure (or deserving of more censure) simply in virtue of the fact that he is taking these very preliminary steps towards executing his plan, even though we can now talk more straightforwardly of conduct that is guided by his plan. ${ }^{8}$ Second, at least if we think about

7 I wondered whether we might deny that D tries to open the wardrobe door as a means to robbing the store-in which case Yaffe need not say that in trying to open the door he is trying to rob the store: but so long as he tries to open the wardrobe because he believes that this will help him achieve his end of robbing the store, it seems to me that he does undertake this action as a means: it is 'an act in the class of means' (p. 218).

8 Of course, even if 'conduct' must involve some material engagement with the world around us, D might have engaged in plan-guided conduct even before he tries to open the wardrobe: perhaps he did some of his planning 
how we should understand the kind of wrongdoing that should concern the criminal law, we can see some reason to regard D's wrongdoing as less serious in such early stages of his criminal endeavour than it will or would be as he comes closer to completing it. The reason is not that he becomes more dangerous, or that success becomes more likely, as he advances further in the enterprise; it is, rather, that wrongdoing of the kind that should concern the criminal law of a liberal polity must consist in some active engagement with the shared social and material world in which we live as citizens, and in which the criminal law has its proper place. ${ }^{9}$ Now D is, of course, actively engaged with the material and social world as he tries to open the wardrobe; he is, to offer a metaphor rather different from the geographical metaphor that Yaffe discusses (pp. 257-73) starting to paint what will (if completed) become the picture of a robbery, or starting to sculpt what will (if completed) become a criminal statue. But he has not yet advanced beyond the preliminary bush or chisel strokes (or perhaps he has not yet even started to paint or to sculpt; he is only getting his tools ready); we cannot yet even see the outlines of the picture or sculpture that is to be; his intended crime has not yet taken anything approaching concrete form; thus he has not yet concretely defined himself, through his engagement with the world, as a robber.

None of this constitutes a determinate argument against Yaffe's view: it is an attempt, rather, to suggest why we should find that view implausible, and to gesture towards another way of understanding the 'act element' in criminal attempts. That is to see the act as being constitutive of the crime - of the wrongdoing that merits criminal condemnation - rather than as playing the evidential role that Yaffe assigns it; it is to see the distinction between 'mere preparation' and attempt as a substantive distinction between kinds of conduct that do not, and those that do, merit criminalization under the general inchoate crime of 'attempt'. But if that is right, we cannot deal with the problem simply by adding another clause to the $G C V$ as an account of what it is to attempt a crime: for as Yaffe notes and others have noted, there is no clear or sharp line to be drawn between 'mere preparation' and 'attempt'; we cannot hope to specify a determinate set of necessary and sufficient conditions for what is to count as an attempt rather than mere preparation. We can say, as English courts have said, that a person commits an attempt only when he has 'embarked on' or is 'in the process of committing' the relevant crime, and agree that when $\mathrm{D}$ tries to open the wardrobe he has not yet embarked on, is not in the process of committing, robbery; ${ }^{10}$ but neither the ordinary extra-legal concept of attempt nor the law itself can provide determinate criteria for what counts as 'embarking on' the commission of any particular crime. Thus while I think that we should understand the act element in criminal attempts along these lines, to do so is to make the law very much less determinate than Yaffe would like. ${ }^{11}$

not simply 'in his head', but by sketching various scenarios on paper; it is hard to see a significant difference in culpability or censurability between purely mental planning and planning done on paper.

9 The qualification 'in a liberal polity', i.e. one that (inter alia) takes privacy and of freedom seriously, is important: other kinds of polity might take more intrusive interest in their members' character and intentions.

10 See Gullefer [1990] 1 WLR 1063, at 1065. Compare also Rowlatt J's comment in Osborn [1920] 84 JP 63, at 63-4, that the attempter must have 'commence[d] to do the very thing'; he must be 'on the job' (although this was said in the context of impossibility rather than of the specification of the act element).

11 See further Duff 1996: chs. 2, 13.5. I am by now unhappy with much of the argument of that book (even more unhappy after reading Yaffe's book); but I still think that in this respect it was working in the right direction. For fuller argument about the significance of action in the criminal law, see Duff 2007: ch. 5. 
$G C V$ provides a plausible and sophisticated core for an account of what it is to attempt, one on which future accounts should build. But it does not, I have argued, offer a plausible complete account: it needs to be supplemented by a distinction between mere preparation and attempt-a distinction that, however, cannot be neatly or sharply drawn through a specification of necessary and sufficient conditions.

\section{Why a Law of Attempts?}

Another respect in which Yaffe's argument is important but incomplete concerns the scope of the criminal law of attempt - or, to avoid confusion, the scope of the general inchoate offence or set of general inchoate offences.

Many complete offences do not require intention - an intention to bring about the elements of the offence. Some offences are so defined that they can be committed either intentionally or recklessly: this is true, for instance, of criminal damage, and of some offences involving physical injury. ${ }^{12}$ In other cases the law distinguishes a complete offence involving intention from a lesser offence involving the reckless causation of the same material harm: thus when murder is defined as requiring an intention to kill (or at least to cause serious physical injury), a lesser offence of manslaughter or culpable homicide is defined to capture the reckless causing of death. When the law defines the general inchoate offence of 'attempt', however, recklessness does not typically suffice: one who is to be guilty of an attempted crime must have intended to commit the relevant complete offence. ${ }^{13}$ This is puzzling. We see good reason to convict of a complete offence both a person who causes damage or injury intentionally, and one who causes such harm recklessly. We also see good reason to convict of an inchoate offence one who acts with the intention of causing such harm but does not actually cause it — such generally good reason that we define a general inchoate offence of 'attempt' to convict such people. Why do we not see equally good reason to convict the person who recklessly creates a risk of causing such harm, who would be guilty of a complete offence if the risk was actualised, of an inchoate offence of recklessness; why, that is, do we not create a general inchoate offence to convict such agents? ${ }^{14}$

This question gains force from Yaffe's explanation of the law of attempts. His focus is on the justification of the Transfer Principle-

If a particular form of conduct is legitimately criminalized, then the attempt to engage in

that form of conduct is also legitimately criminalized (p. 21).

The justification of criminalizing a form of conduct involves two claims-

Criminalization of a type of conduct is legitimate if (1) Censure by the state of every unexcused and unjustified token of that type of conduct is deserved, and (2) Some of the

12 See e.g. Criminal Damage Act 1971, s. 1 (and Model Penal Code \$220.3); Offences against the Person Act 1861, s. 20 (and Model Penal Code $\$ 211$ — which also covers attempts and endangerments).

13 For rare exceptions see Colo. Rev. Stat. §18-2-101(1)), applied in People v Thomas 729 P.2d 972 (1986) (Yaffe pp. 47-8); and the Scottish case of Cawthorne [1968] JC 32 (D fired a gun into a populated room, with no intent to kill; but he was convicted of attempted murder, on the grounds that he acted with a mens rea that would have made him guilty of murder had he caused death. For an academic argument to the same end, see Stuart 1968.

14 Our laws do contain inchoate offences of recklessness, some quite general (see e.g. Model Penal Code $\$ \S 211.2$, 220.2(2); but none approach the generality of the law of attempts. 
unexcused and unjustified tokens of that type of conduct are legitimately sanctioned by the state in some way or other' (p. 32).

What justifies the Transfer Principle is, then, the further claim that a failed attempter shares two relevant properties with one whose criminal attempt succeeds: each similarly deserves censure in virtue of his 'improper mode of recognition and response to legal reasons', and each deserves to be sanctioned because he is 'guided in [his] conduct by [his] mode of recognition and response to reasons in a way that brings [him] close to completion' (p. 33). ${ }^{15}$ For whether or not my attempt succeeds, I display the same improper mode of recognition and response to legal reasons, and am guided by that mode of recognition and response in a way that brings me close to completion.

Now this kind of explanation, in terms of the agent's response to relevant reasons, seems to me absolutely right. The criminal law addresses us as agents who can recognise, respond to, and be guided by reasons; it speaks of the reasons by which we should or should not be guided; ${ }^{16}$ and it condemns us for being guided (for guiding ourselves) by wrong reasons or for failing to guide ourselves by the right reasons. However, it is radically incomplete as an explanation for a law of criminal attempts, if attempts are defined as requiring an intent to commit the relevant complete offence: for what this line of argument seems to justify is precisely the extensive law of inchoate crimes suggested above. Someone who recklessly injures another person, or recklessly damages another's property, deserves censure and sanction because he has failed to recognise, or failed to respond to, reasons that - as the criminal law declares - ought to guide his conduct, and because he guides his conduct to completion by his defective recognition of or response to those reasons; but in just the same way one who recklessly endangers another's physical safety or property fails to recognise or to respond to those reasons, and guides his conduct close to completion by that defective recognition and response.

It is true that his conduct is not guided by any commitment to bring about the result whose occurrence would constitute the completion of the crime: he is not committed to injuring another person or to damaging property in the way that one who attempts such crimes is committed; the fact that the injury or damage does not ensue does not render his enterprise a failure. ${ }^{17} \mathrm{We}$ might therefore say that, whereas one who attempts to commit a crime guides his conduct by wrong reasons, one who acts recklessly fails to guide his conduct by right reasons. The former takes as at least his immediate end, and so treats as a good reason for action, something (injury to another person, damage to another's property) that is in the criminal law's eyes not a (normative) reason for action at all. By contrast, the reasons for which the latter acts (the reasons for which he takes the risk) might be perfectly legitimate; what is wrong with his conduct is that he fails to treat the risk that he creates as a good reason not to act as he does. But the same is true of the person who causes the harm that he takes a risk of causing: both exhibit just the same improper mode of

15 Although it becomes clear later in the book, given Yaffe's account of the justification of criminal punishment, that desert is not sufficient to make the imposition of sanctions legitimate (see 313-6).

16 My only quibble with Yaffe here is that in the case of the criminal law these are not always or typically legal reasons: when the law defines murder, or rape, or theft as a crime it does not offer us new, distinctively legal reasons for refraining from such wrongs, but rather appeals to the pre-criminal reasons that we already had, and by which we should already be guided, not to commit such wrongs. In general, the criminal law presupposes, rather than creating, reasons to refrain from what it defines as crimes: see Duff 2007: 84-9.

17 Though we will see in s. 3 that there are some puzzles about Yaffe's account of the commitments that we must be able to attribute to the attempter. 
recognition and response to legal reasons'; both are guided in just the same way by that improper mode of recognition and response; if the former deserves censure and sanction, so does the latter.

This suggests that whilst the Colorado attempt statute that Yaffe quotes does not capture the (ordinary, extra-legal) meaning of 'attempt', it does capture the kind of general inchoate offence that Yaffe's argument would justify: what that offence should require is 'the kind of culpability otherwise required for commission of an offense', and conduct that comes close enough to the completion of an offence. ${ }^{18}$ It is true that, if we extend the law beyond 'last act' cases to capture cases in which whether the actual creation of the risk depends on further actions by the agent, we might need to require an intention to commit those further actions: if, for instance, the law is to convict of this inchoate offence not only the person who actually fires the shot that endangers the life of another, but also the person who is stopped just before he fires, it should convict him only if he intended to fire the gun. But we do not need to require an intention to commit the complete offence of injuring another person; and we could anyway limit any such law to 'last act' cases in which the agent does create the relevant risk. ${ }^{19}$

Yaffe notes the possibility that the argument he offers for the Transfer Principle (which itself covers only attempts) might also

show that we are justified in criminalising harmless, reckless or negligent behaviour, not rising to the level of attempt, which would have involved a completed crime had it been harmful (p. 44).

The only doubt that he expresses about this is that we might not be justified in sanctioning any 'tokens of reckless or negligent acts that have a low probability of harm, and do not cause harm' -in which case we would not be justified in criminalizing such acts (p. 44). Even if that is true, however, that is surely not the relevant 'type of conduct' about which we are to ask whether we are justified in sanctioning some of its tokens (p. 32): the relevant type of conduct is reckless (or negligent) conduct of such a kind that the agent would have committed a complete offence if the risk that his conduct created had been actualised; and while some such conduct might create only quite a low risk, some will make the occurrence of harm very likely. ${ }^{20}$ Since we can legitimately sanction at least some tokens of that type, we can on Yaffe's account legitimately criminalize the type as a whole.

Yaffe's other response to the possibility that his argument would justify a much broader law of inchoate crimes is that this 'does not provide an objection to anything to be said here', since 'that there are good reasons to criminalize certain forms of reckless and negligent endangerment does not show that there are not also good reasons to criminalize attempts' (p. 45). But this is too quick, as an admittedly unfair analogy will illustrate. Suppose I aim to justify a law that makes it a crime for members of a certain group (a group defined, perhaps, by its race or gender or sexual orientation) to $\Phi$. Someone then points out that the arguments by appeal to which I justify such a

18 Colo. Rev. Stat. §18-2-101(1); see n. 15 above.

19 For a radical version of this possibility, see Alexander and Ferzan 2009. On their account, there is just one kind of crime, conduct that irrevocably unleashes an unjustified risk of harm to a legally protected interest, and one kind of fault, recklessness; no distinction is drawn between conduct that is intended to do harm and conduct that creates a recognised risk of harm.

20 I leave aside here the issue of whether recklessness should be defined in terms of the creation of a 'substantial' risk, or merely an unjustified risk: compare Model Penal Code \$2.02(2)(c) with Alexander \& Ferzan (op. cit. n. 21 above), 25-7. 
law would justify a much broader law, making it a crime for anyone to $\Phi$. I reply that that might be true, but does not constitute an objection to my proposed law. That reply would-predictably and reasonably-leave my critic unimpressed. To justify my proposed law I must show not just that we have good reason to criminalize at least the range of conduct that it covers, but also that that reason justifies the criminalization only of that range of conduct: for otherwise I will face the justified criticism that my proposed law is unjustly discriminatory in criminalizing one category of agents, but not another category whom we have just the same reason to criminalize. But this is what Yaffe does: he argues for a law that criminalizes attempts to commit crimes, by appealing to reasons that would justify a far broader law of inchoate crimes on the Colorado model; whilst he gives us good reason to criminalize at least attempted crimes, he gives us no reason to limit the law of inchoate crimes to attempts. The point here is not simply that we might have reason to criminalize reckless endangerments as well as criminal attempts. It is that we have the very same reason to criminalize both kinds of conduct: for the commonality between the person who takes a reckless risk of causing harm without actually causing it and one whose reckless risk-taking does cause harm is precisely the same as the commonality between one whose attempted crime fails and one who succeeds; within each pair, the two agents display just the same 'improper mode of recognition and response to legal reasons', and are guided in just the same way by that 'mode of recognition and response to reasons'.

The argument sketched here is admittedly not identical to, but seems to be a close relative of, the 'Same Act' and 'Same Attempt' arguments that Yaffe later offers (ch. 12) to justify inter alia punishing non-last act attempts as severely as they would have been punished had they got as far as the last act. He imagines a last-act attempter complaining if a non-last-act attempter receives a lighter punishment-

Why is he being given a lesser punishment than I am? After all, we both tried to commit the crime, and we did it for the very same reasons and with the same results (p. 329).

Analogously, we can imagine someone punished for attempted criminal damage, under a law of attempted crimes that requires an intention to commit the offence, complaining when he sees that someone who acted with a kind of recklessness that would have made him guilty of just the same complete offence of criminal damage had he actually caused harm, but caused no damage, is not guilty of any crime-

Why is he not criminally liable when I am? After all, we both acted in a way that would have made us guilty of the same crime had we caused damage, and came similarly close to causing damage without actually causing it.

This question deserves an answer, if we are to avoid the charge that the law is unfair as between these two people, and if Yaffe's justification of a law of attempts is to be complete; but it is not clear what answer he could give.

If the argument of this section is sound, it leaves two possible ways forward. One would be to argue for a radically extended law of inchoate crimes, on the Colorado model, ${ }^{21}$ in which case Yaffe's sophisticated and plausible discussions of what it is to attempt to commit a crime would lose their relevance to the criminal law (although they would of course retain their philosophical interest). The other would be to offer an argument for a narrower general law of inchoate crimes,

21 Or indeed the Alexander and Ferzan model (see n. 19 above): but nothing said here argues in favour of their denial that the law's definitions of offences should draw any distinction between intention and recklessness, or between conduct that does and conduct that does not actually cause harm. 
by showing how the defining feature of such a narrower law - the requirement for an intention to commit the complete offence - takes on a distinctive importance if the crime is not completed. We might find a basis for such an argument in the idea of commitment, and the significance that it can have when the course of conduct in question is not completed. If the metaphor of crime as a painting or sculpture that I suggested in $\mathrm{s} .1$ has any force, ${ }^{22}$ we might say that if the painting or sculpture is not completed, we can discern its emerging shape and form only through the artist's intentions (her commitment to the final figure). Given such a commitment, we can see the halfcarved block of stone or the partially painted canvas as an incomplete, etiolated version of the statue or portrait that it will become (if it is completed as planned); but in the absence of such a commitment, we cannot see this. We might see a potential in the stone or canvas; we might see how it could become or could be made into a statue or portrait; but we cannot see it as a not yet complete statue or portrait. If what makes inchoate crimes worth punishing is their relationship to the complete crimes of which they are inchoate versions, then this might suggest why we have stronger reasons to criminalize attempted crimes than we have to criminalize conduct that creates an unjustified risk of criminal harm but is not intended to cause such harm: the attempt is more intimately related to the complete offence than is the merely risky action.

However, the role played by the idea of commitment in Yaffe's account generates the third, and final, set of issues that I want to discuss.

\section{Attempts and their Circumstances}

The $G C V$, expressed very roughly, tells us that $\mathrm{D}$ attempts to commit a crime (and thus commits a criminal attempt) if and only if his conduct is guided by a commitment to each of the elements of the complete crime: for each element, it must be the case either that that element is 'included in' D's intention or that 'if D's intention plays its proper causal role' that element will ensue; and D must be guided by such a commitment to that element (p. 73).

It is, with one complication that we cannot pursue here, easy enough to see how this criterion deals with what analysts typically class as the 'act element' and the 'result element' of the crime: $\mathrm{D}$ attempts to bring about a specified result $\mathrm{X}$ only if he intends, through some voluntary act, to cause $X .{ }^{23}$ But what of the circumstantial elements of the offence: those elements that, in Yaffe's neat way of drawing the circumstance-result distinction, the prosecution must prove to have been in place (to have existed or occurred at the time of the alleged crime), but need not prove to have

22 A very large 'if', some might say, and not one that I can do nearly enough to justify here; it is a way of trying to flesh out some of the arguments I offered in Duff 1996, especially in ch. 13.

23 The complication concerns cases in which $\mathrm{D}$ foresees that in acting as he intends to act he will certainly cause $\mathrm{X}$ as a side-effect, but does not act with the intention of causing $\mathrm{X}$ - so that were $\mathrm{X}$ not to ensue, he would be surprised, but would not just for that reason count his enterprise a failure. So long as it is logically possible that D's intention plays its proper causal role 'in making the world match its content' without X occurring, Yaffe argues, D does not attempt to bring $X$ about; but we might still hold him guilty of a criminal attempt (see at $n$. 5 above on the commission-guilt distinction) if what D does is 'just as bad as' an attempt (pp. 119-24). I have grave doubts about this device, of mandating courts to convict a person of an offence that he did not commit, if it judges his conduct to be 'just as bad as' that of someone who does commit the offence, but cannot pursue the issue here. 
been caused by D? Familiar circumstantial elements, which have generated heat and confusion among theorists of criminal attempt, include the fact that the person whom D sexually penetrates does not consent to the penetration, as an element of rape; the fact that the property I appropriate belongs to another person, and the fact that the owner does not consent to my taking, as elements of theft; and the fact that the goods I receive are stolen goods, as an element of handling stolen goods. We can distinguish eight possible scenarios involving such circumstantial elements (C).

(1) C's existence is part of D's intention (he intends that the penetration be non-consensual; or that the property he appropriates belongs to another; or that the goods he receives be stolen goods); C exists; and D completes his intended course of action (penetration, appropriation, reception).

(2) C's existence is part of D's intention; C exists; D is prevented from completing his intended course of action.

(3) C's existence is part of D's intention; C does not exist (the person consents to penetration; the property is D's own; the goods are not stolen goods); but D completes the penetration, appropriation, or reception.

(4) C's existence is part of D's intention; C does not exist; D is prevented from completing the penetration, appropriation, or reception.

(5) C's existence is no part of D's intention but he is reckless as to whether it exists: he realises that there is a risk that the other person does not consent to the penetration, that the property might belong to another person (or that the other person does not consent to his taking it), or that the goods he intends to receive might be stolen goods - and that risk is one that it is unreasonable for him to take. $\mathrm{C}$ exists; and $\mathrm{D}$ completes his intended of action (penetration, appropriation, reception).

(6) C's existence is no part of D's intention but he is reckless as to whether it exists; C exists; $\mathrm{D}$ is prevented from completing the penetration, appropriation, or reception.

(7) C's existence is no part of D's intention but he is reckless as to whether it exists; C does not exist; D completes the penetration, appropriation, or reception.

(8) C's existence is no part of D's intention but he is reckless as to whether it exists; C does not exist; $\mathrm{D}$ is prevented from completing the penetration, appropriation, or reception.

Recklessness as to the existence of $\mathrm{C}$ suffices for the commission of the relevant complete crime, of rape, theft or handling stolen goods. ${ }^{24}$

Cases (1) and (5) need not detain us: D clearly commits and is clearly guilty of the complete offence. In case (2) D is clearly guilty of an attempt to commit the crime-guilty under existing law, guilty by the criteria specified in the $G C V$, and rightly so. $\mathrm{D}$ is committed not merely to the sexual penetration of this person, or to the appropriation or reception of this property, but to the non-consensual penetration of the person, to the appropriation of another's property, to receiving stolen goods; his conduct is guided by that commitment; and (so we can suppose) he comes close enough to completing the crime to count as attempting it.

Cases (3) and (4) have sometimes confused courts, who have thought that when an essential element of the complete crime is missing in this way, thus rendering its commission impossible

24 We could of course multiply scenarios in which the complete offence requires, for instance, knowledge of C's existence; or in which negligence suffices; or in which liability is strict as concerns C, so that D can be guilty even if he does not realise that $\mathrm{C}$ exists and could not reasonably be expected to realise it. But the scenarios given here, involving only intention and recklessness, will suffice for present purposes. 
in the circumstances, the defendant should not be convicted of attempting to commit it. As Yaffe shows (ch. 5), this is indeed a confusion: D's intention commits him to the existence of C, since it is part of his intention that $\mathrm{C}$ should exist; his conduct is guided by that commitment; and he is rightly convicted of a criminal attempt if, as in case (3), his commission of the complete crime is frustrated by C's non-existence, or if, as in case (4), his attempt would have been thus frustrated had it not been interrupted. Cases (1) - (5) were included only for the sake of completeness: the problems that concern me here are raised by cases (6) - (8).

It has seemed to many (and seems to me) intuitively plausible that D commits, and should be held guilty of, a criminal attempt in case (6), but not in case (7) - and therefore, a fortiori, not in case (8), which we can also henceforth ignore. ${ }^{25}$ If $\mathrm{D}$ attempts the sexual penetration of someone who does not in fact consent to it; he is reckless as to whether she consents, and would commit a rape if he succeeded in the penetration; but he is prevented from completing it: surely we should hold that he has attempted to rape her; surely the law should convict him of attempted rape. So too with the cases of theft and handling stolen goods. ${ }^{26}$ But on the other hand, if D attempts the sexual penetration of someone who does in fact consent to it, though he is reckless as to whether she consents, he is surely not an attempted rapist, whether or not he completes the penetration: he is, to put it mildly, morally lacking in his sexual attitudes and conduct; he takes a serious risk that what he is doing or trying to do constitutes the serious wrong of rape; but, luckily for both him and the other person, it is instead a consensual sexual encounter.

The challenge then is to find a coherent and plausible account of criminal attempts that will generate these intuitively plausible results; part of what can make that challenge seem daunting is the fact that if we are insist that in case (6) D intends to commit, and is committed to commit, the complete crime, but that in case (7) he has no such intention or commitment, we must show how what $\mathrm{D}$ intends to do or is committed to doing depends not just on the subjective content of his own attitudes, beliefs and other mental states, but on the way the world is - on whether or not $\mathrm{C}$ actually obtains.

It might also seem that the $G C V$ cannot cope with such cases. For, first, $\mathrm{C}$ is not included in D's intention; he is not committed to it by that route. If we then ask whether C would exist if D's intention played its proper causal role, the answer is less clear (at least to me). What matters, as we have seen, is whether it is logically possible that D's intention plays its proper causal role 'in making the world match its content' without C existing (p. 120): but how can we determine that? If we take as given the fact that $\mathrm{C}$ exists (that the other person does not consent to penetration), then if D's intention plays its proper causal role he will sexually penetrate the other person, and that penetration will be non-consensual; and since he is also reckless as to her consent, he will thus commit the complete offence of rape. Or should we instead say that, since in cases like (6) what D actually does falls both substantively and temporally short of committing the complete offence, there will always be a period of time, however small, in which the world could logically change? At $t_{1} \mathrm{D}$ is forcibly prevented from completing the penetration, appropriation or reception that he intends; that completion would have occurred at a later time $t_{2}$; and however small the temporal gap between $t_{1}$ and $t_{2}$, it is logically possible that $\mathrm{C}$ would have ceased to exist during

25 That is, if D should be acquitted in case (7), he should clearly also be acquitted in case (8); and if he should be convicted in case (7), there is no reason not also to convict him in case (8).

26 So long, of course, as we agree that recklessness should suffice for the complete offence: if it should not, then it clearly should not suffice for the attempt either. 
that time - that the other person would have consented, that the goods would have ceased to be stolen, etc.. I confess that I don't know the answer to this question, though I suspect that it is No; and it is not an answer that Yaffe offers (we will turn to his answer shortly). But even if we could say that, in the case in which $\mathrm{C}$ exists, $\mathrm{D}$ is committed to $\mathrm{C}$ in the sense that it would exist if his intention played its proper causal role, it is hard to see how D can satisfy the second limb of the $G C V$ - the Guidance Criterion: for it is surely not the case that $\mathrm{D}$ is guided by his 'commitment' to $\mathrm{C}$. It is true that his belief that $\mathrm{C}$ does or might exist will often help to guide his conduct: if he suspects that the person whom he tries to penetrate might not consent, he might take precautions against her potential resistance, or use a kind or degree of force that he would not have otherwise used; if he suspects that the property that he is trying to appropriate belongs to a non-consenting other, or that the goods he aims to receive are stolen goods, he might take steps to shield what he is doing from public or official gaze. But, first, it would seem odd to say that he is being guided by a 'commitment' to $C$; one would more naturally suppose that to be guided by a commitment to $\mathrm{C}$ is to structure one's actions with a view to ensuring that $\mathrm{C}$. Second, it is anyway not always the case that someone who suspects the existence of a circumstance which is such that, if it exists and he completes his intended course of action, he will commit a complete offence is led by that suspicion to change his behaviour in any way; and it would be odd indeed to convict of criminal attempt one whose suspicion does make a difference to his conduct, but to acquit one to whose conduct that suspicion makes no difference.

Yaffe argues, however, that the $G C V$ can provide a plausible solution to such cases. ${ }^{27}$ In case (6), in which $\mathrm{C}$ does exist, we can properly talk of D's commitment: for D is committed both to 'Non-Reconsideration', i.e. 'to not reconsider [his] intention on the grounds that [he] believes' C to exist; and to 'Not Complaining', i.e. 'to not complaining that the world fails to be as intended in light of the fact that' C exists (p. 148). More precisely, whilst D presumably cannot complain that the world fails to be as intended, in virtue simply of the fact that $\mathrm{C}$ exists, if he acted in the belief that $\mathrm{C}$ existed (or even with the suspicion that $\mathrm{C}$ might exist), matters are not so simple as far as non-reconsideration is concerned: for $\mathrm{D}$ incurs that commitment not simply in virtue of his belief or suspicion that $C$, but only if the supposed fact or risk that $C$ is 'salient' for him (pp. 1501). Now I am not sure just what Yaffe counts as salience: $C$ is certainly salient for $D$ if he takes it to give him some reason for action, and is not salient if D 'could not care less' that $C$ exists ( $p$. 150); but I don't know whether $C$ is to count as salient just so long as D has some concern about $\mathrm{C}$, even if he does not see that it as a source of reasons for action. Suppose, for instance, that D would prefer $\mathrm{C}$ not to exist: he would prefer that the sexual penetration be consensual, or that the property he takes be his own (he takes an umbrella hoping that it is his, but realising that it might belong to another), or that the goods he receives not be stolen goods. However, this preference is detached from his agency, in that he does not see C's (supposed or possible) existence as giving him reason to alter his conduct: is $\mathrm{C}$ then 'salient' for him? But we need not settle this question here: for our purposes, it will suffice to take as examples of non-salience relatively extreme cases like that of the 18-year-old having sex with a 15 -year-old partner in a jurisdiction in which it is a

27 I should note that he focuses on cases in which D believes $\mathrm{C}$ to exist, rather than on cases in which D is merely reckless as to whether $\mathrm{C}$ exists (which on orthodox understandings of recklessness requires only the suspicion that $\mathrm{C}$ exists). However, if he is to deal plausibly with the attempted rape case, his account will need to cover cases of recklessness as well as those of belief; and if it works for cases of belief, I think it will also work for cases of recklessness. 
crime to have sexual intercourse with someone under the age of 16 (p. 153), and think of agents for whom the (supposed or possible) non-consent of the person whom they try to penetrate, or the (supposed or possible) fact that the property they take is or might be another's, or is or might be stolen, is as insignificant as is his partner's age to the 18 -year-old. ${ }^{28}$

Yaffe draws three conclusions from his discussion of such cases. First, if $\mathrm{C}$ is salient for D, and exists, $\mathrm{D}$ commits a criminal attempt because he has the requisite (de re) intention to commit a crime: he intends [to $\Phi$ in $C$ ] - [to sexually penetrate a non-consenting person], [to appropriate property belonging to another], or [to receive stolen goods]. Second, if C is non-salient for D, he does not commit a criminal attempt, since he lacks the requisite intention: it is not now true that he intends [to $\Phi$ in $\mathrm{C}$ ]. Proof of his belief (or suspicion) that $\mathrm{C}$ creates a rebuttable presumption that he intends [to $\Phi$ in $C$ ], but he can rebut that presumption by evidence that $\mathrm{C}$ was not salient for him (pp. 152-4). Third, and even more strikingly, no such intention can be ascribed to D in cases (7) and (8), in which $\mathrm{C}$ does not exist. For the Commitment to not Complaining should be understood not as a 'wide scope' commitment [to not complaining that if $\mathrm{C}$, the world fails to be as intended], but as a 'narrow scope' commitment to not complaining which I incur only if $\mathrm{C}$ in fact obtains: 'If [C], then one is committed to not complaining that, in light of [C], the world fails to be as intended'. In a case in which $\mathrm{C}$ does not obtain, $\mathrm{D}$ therefore incurs no such commitment: so he does not have the de re intention [to $\Phi$ in $\mathrm{C}$ ], and does not commit a criminal attempt (pp. 156-7).

That third conclusion offers us an impressively neat solution to the problem of distinguishing case (6) from case (7). However, the solution is viable only the first two conclusions are sound; and I do not think that they are.

First, while the commitments to Non-Reconsideration and to Not Complaining do seem to be genuine commitments that $\mathrm{D}$ incurs, it seems very odd indeed to count them as commitments to $\mathrm{C}$, or to the existence of C. We might say that D is committed [to $\Phi$ even if C] or [to $\Phi$ despite $\mathrm{C}$ ]: but it is hard to see how that could be described as a commitment to C-especially if D acts in the hope that $\mathrm{C}$ does not obtain.

Second, even if we could accept that $\mathrm{D}$ is 'committed' to $\mathrm{C}$ in the sense that his commitment includes $C$, in the way that it does if he is committed [to $\Phi$ despite $C$ ], he still does not satisfy the Guidance Criterion: it is still not true that his conduct is guided by his commitment to C. More precisely, if $\mathrm{C}$ is a circumstance that $\mathrm{D}$ believes to exist or suspects might exist, but that he does not see as providing him with any reason for action, then there is no difference as far as guidance is concerned between a commitment simply [to $\Phi$ ] and a commitment [to $\Phi$ despite $C$ ]; which is surely to say that the latter more complex commitment does not guide his conduct.

Third, given the second conclusion that Yaffe draws, it seems that the more callous, the more indifferent, $\mathrm{D}$ is, the greater the chance that he will not commit a criminal attempt. For if he cares about whether the other person consents to sexual penetration, and sees her possible non-consent as a reason against persisting (albeit not a strong enough reason set against his own desires), then

28 I found the other example with which Yaffe illustrated this point - that in which I believe that the governor of California, to whom I intend to give \$1,000,000, has an Austrian accent (pp. 150-1) unhelpful: partly because the putative de re intention would not be, as Yaffe has it, [to pay the Austrian-accented person \$1,000,000], but [to pay an Austrian-accented person $\$ 1,000,000$ ]; and partly because the reason why neither we nor I would naturally describe my intention thus is surely, and simply, that that would not be a helpful way of enabling my hearer to identify the intended recipient of my generosity. 
her non-consent is salient; if she does not consent, he commits an attempted rape (if his attempt at sexual penetration fails). But if he does not care in the least about her consent or lack of it, that circumstance is non-salient for him: he therefore does not commit attempted rape, and must be acquitted if he can persuade the court of his callous indifference. So too with property offences: someone who cares about whether the property that he takes is another's, or about whether the other consents, or about whether the goods that he receives are stolen, commits attempted theft or handling if the relevant circumstance obtains; but someone who is utterly indifferent to such matters does not commit an attempt, even if he truly believes that what he is trying to take is a non-consenting other's property, or that what he tries to receive are stolen goods. That result is bizarre; indeed, I'm inclined to see it as a reductio. ${ }^{29}$

If the argument sketched in this section is sound, we have here a third way in which the $G C V$ account is at least incomplete. We should surely say, independently of the criminal law, that one who tries to sexually penetrate an in fact non-consenting other person, realising that she does not or might not consent, tries to rape her, even if her lack of consent is not part of his intention; and the criminal law should surely convict such a person of attempted rape: but Yaffe's account does not provide plausible grounds for convicting him, or for ascribing an attempted rape to him. The $G C V$ provides a persuasive account of what it is to attempt to bring about a certain result (or, if the argument of s. 1 is right, would provide such a persuasive account if supplemented so that it can distinguish mere preparations from attempts); but it does not help us to understand when and why it is proper to include circumstantial aspects of the completed action or crime in our account of what the agent attempts to do.

How could we remedy this lack in Yaffe's account? I have argued that we can deal with the problem of the circumstantial elements of an attempt (and other problems) by understanding the 'intent to commit an offence' which criminal attempts require as 'an intention such that the agent would necessarily commit an offence in carrying it out' ${ }^{30}$ This sounds quite like Yaffe's account of the Commitment Criterion, but a crucial difference is that in asking whether D would commit an offence in carrying her intention out, we take as given both the world as it is at the time of D's action and D's attitudes and beliefs at that time: so if D attempts sexual penetration of an in fact non-consenting other, and is reckless as to whether she consents, we ask whether in that context $\mathrm{D}$ would commit rape in completing the intended sexual penetration; and since the answer to that question is 'Yes', D is guilty of attempted rape. Note, however, that if the other person in fact consents, D is not guilty of attempted rape (he would have been guilty only if her lack of consent had been part of his intention), since the completed penetration would not constitute rape. Nor is he guilty if the other person does not in fact consent, but he is not reckless as to her consent (he acts, perhaps, in the mistaken but reasonable conviction that she consents): although in that case he would indeed commit the actus reus of rape in completing the intended penetration, he would not commit rape, since he would lack the requisite mens rea.

Yaffe's central objection to this suggestion is that it involves positing a commitment that ' $i s$ not intention-based' (p. 139): that is, it takes D to be committed to the other's lack of consent, or to being reckless as to her consent, but does not ground that commitment in D's intention. Now I

29 Or might Yaffe still convict him of an attempt, although he does not commit one, because what he does is 'just as bad' as what someone for whom is $\mathrm{C}$ is salient does (see n. 23 above)?

30 Duff 1996: 22: on the circumstantial aspects of attempts, and on 'impossible attempts' whose impossibility lies in the absence of a circumstantial element, see 25-9, 206-19; for Yaffe's criticisms see Yaffe pp. 137-42. 
agree that it would be a mistake to ascribe such a commitment to D without grounding it in what D intends; and I agree that my account of why we should say that D acts 'with intent to commit an offence' of rape, if the person whom he tries to penetrate does not consent and D is reckless as to her consent, does not ascribe to D an intention-based commitment to either of those elements of the complete offence of rape. That is not, however, because I would ascribe a commitment to $\mathrm{D}$ that is not intention-based; it is because I do not think that, in order to convict D of attempted rape, we must be able to ascribe any such commitment to him. I have argued in this section that Yaffe fails to offer us a viable account of how D is 'committed' to the circumstantial elements of the complete crime - an account that generates plausible conclusions about when D can properly be said to attempt to commit the crime. The solution, I suggest, is not to find a new, even more sophisticated account of commitment that will produce the right results; nor to hold that D does not commit an attempted rape when he tries to penetrate an actually non-consenting other and is reckless as to her consent; but to recognise that I can attempt to commit a crime without being committed to all the elements of that crime.

\section{Concluding Remark}

The discussion in the previous three sections focused on three ways in which I think the Guiding Commitment View fails to provide a complete or adequate account either of what it is to attempt to act or of the conditions under which a person commits (or can be properly held to be guilty of) a criminal attempt. It generates too broad a conception of the 'conduct element' in attempt, since it does not generate an adequate distinction between attempts and merely preparatory conduct. It limits the general law of inchoate crimes to 'attempts', understood (as attempts should indeed be understood extra-legally) as requiring an 'intent to commit' the complete offence; but we are not given any adequate justification for such a narrow law of inchoate crimes, rather than a broader one that requires only the same kind of fault as is required for the complete offence. And, finally, it cannot explain why and when it is proper to include in our (or the law's) description of what an agent attempted to do circumstantial elements that were not part of his intention.

The $G C V$ is a major achievement: any complete account of criminal attempts will, I am sure, need to include it or something very like it. But the account of criminal attempts that Yaffe bases on it is still in some very important respects radically incomplete.

\section{References}

Alexander, L., Ferzan, K. K., with Morse, S. (2009). Crime and Culpability: A Theory of Criminal Law. Cambridge: Cambridge University Press

Duff, R. AQ. (1996). Criminal Attempts. Oxford: Oxford University Press (2007). Answering for Crime: Responsibility and Liability in the Criminal Law. Oxford: Hart Publishing

Hall, J. (1940). 'Criminal Attempt—A Study of Foundations of Criminal Liability'. Yale Law Journal, 49, 789-840

Stuart, D. (1968). 'Mens Rea, Negligence and Attempts'. Criminal Law Review, 647-62 Yaffe, G. (2010). Attempts in the Philosophy of Action and the Criminal Law. Oxford: Oxford University Press 